Article

\title{
Curcumin Analogue L48H37 Suppresses Human Osteosarcoma U2OS and MG-63 Cells' Migration and Invasion in Culture by Inhibition of uPA via the JAK/STAT Signaling Pathway
}

\author{
Ko-Hsiu Lu ${ }^{1,2,+} \oplus^{\circ}$, Heng-Hsiung Wu ${ }^{3,4,5,+}$, , Renn-Chia Lin ${ }^{1,2,6}$, Ya-Chiu Lin ${ }^{7}$, Peace Wun-Ang Lu ${ }^{8}$, \\ Shun-Fa Yang $7,9, *$ (iD and Jia-Sin Yang $7,9, *$
}

1 Department of Orthopedics, Chung Shan Medical University Hospital, Taichung 402, Taiwan; cshy307@csh.org.tw (K.-H.L.); cshy594@csh.org.tw (R.-C.L.)

2 School of Medicine, Chung Shan Medical University, Taichung 402, Taiwan

3 Graduate Institute of Biomedical Science, China Medical University, Taichung 404, Taiwan; henghsiungwu@mail.cmu.edu.tw

4 Research Center of Tumor Medical Science, China Medical University, Taichung 404, Taiwan

5 Center for Molecular Medicine, China Medical University Hospital, Taichung 404, Taiwan

6 Division of Hyperbaric Oxygen Therapy and Wound Medicine, Chung Shan Medical University Hospital, Taichung 402, Taiwan

7 Institute of Medicine, Chung Shan Medical University, Taichung 402, Taiwan; champion-one@hotmail.com

8 Morrison Academy Taichung, Taichung 406, Taiwan; lup@mca.org.tw

9 Department of Medical Research, Chung Shan Medical University Hospital, Taichung 402, Taiwan

* Correspondence: ysf@csmu.edu.tw (S.-F.Y.); gazn_sheep@yahoo.com.tw (J.-S.Y.); Tel.:+886-4-24739595 (ext. 34253) (S.-F.Y.)

+ These authors contributed equally to this work.

\section{check for}

updates

Citation: Lu, K.-H.; Wu, H.-H.; Lin, R.-C.; Lin, Y.-C.; Lu, P.W.-A.L.; Yang, S.-F.; Yang, J.-S. Curcumin Analogue L48H37 Suppresses Human Osteosarcoma U2OS and MG-63 Cells' Migration and Invasion in Culture by Inhibition of uPA via the JAK/STAT Signaling Pathway. Molecules 2021, 26, 30. https://dx.doi.org/10.3390/ molecules 26010030

Academic Editor: Silvie Rimpelová Received: 23 October 2020

Accepted: 19 December 2020

Published: 23 December 2020

Publisher's Note: MDPI stays neutral with regard to jurisdictional claims in published maps and institutional affiliations.

Copyright: (C) 2020 by the authors. Licensee MDPI, Basel, Switzerland. This article is an open access article distributed under the terms and conditions of the Creative Commons Attribution (CC BY) license (https: / / creativecommons.org/ licenses/by/4.0/).

\begin{abstract}
Osteosarcoma, the most prevalent malignant bone tumor in the pediatric age group, is responsible for the great majority of cancer-associated deaths owing to its highly metastatic potential. The anti-metastatic effects of the new curcumin analogue L48H37 in human osteosarcoma are still unknown; hence, we investigated whether L48H37 represses human osteosarcoma cells' biological behavior of migratory potential and invasive activities and attempted to delve into its underlying mechanisms. L48H37 up to $5 \mu \mathrm{M}$ inhibited, without cytotoxicity, the motility, migration, and invasion of human osteosarcoma U2OS and MG-63 cells. In U2OS cells, the human protease array revealed an obvious decrease in urokinase plasminogen activator (uPA) expression after L48H37 treatment, and $\mathrm{L} 48 \mathrm{H} 37$ actually reduced the level, protein and mRNA expression, and promoter activity of uPA dose-dependently. L48H37 decreased the phosphorylation of STAT3, JAK1, JAK2, and JAK3 in U2OS cells, but did not affect the phosphorylation of ERK, JNK, p38, and Akt. Using colivelin, an activator of STAT3, the L48H37-induced decrease in UPA and migratory potential could be countered as expected. Collectively, L48H37 represses the invasion and migration capabilities of U2OS and MG-63 cells by the suppression of uPA expression and the inhibition of JAK/STAT signaling. These results suggest that $\mathrm{L} 48 \mathrm{H} 37$ may be a potential candidate for anti-metastatic treatment of human osteosarcoma.
\end{abstract}

Keywords: L48H37; migration; osteosarcoma; JAK/STAT; uPA

\section{Introduction}

Osteosarcoma, mainly arising from the metaphysis of the distal femur or proximal tibia, is the most prevalent bone malignancy, with peak incidence in the second decade of life and the second incidence peak in older adulthood [1-3]. While the evaluation of osteosarcoma patients should include plain radiographs and magnetic resonance imaging of the entire affected bone, computed tomography of the chest and bone scan are needed for metastatic disease [1,4]. As a potent metastatic tumor, a cure is rare after surgical en bloc resection or amputation of the extensively diseased extremity to achieve a complete 
radical excision, which has been the treatment of choice for osteosarcoma [4,5]. Based on radiological staging, the combination of limb-sparing surgery and effective chemotherapy for osteosarcoma has increased long-term survival rates to approximately $68 \%$ recently $[5,6]$. However, early metastatic transfer to the lungs is still responsible for most treatment failure and is accountable for one of the most lethal pediatric malignancies [7].

Cancer metastasis involves highly coordinated, sequential, and complex pathways that are collectively termed the metastasis cascade [8], including the detachment of malignant cells, epithelial-mesenchymal transition (EMT), invasion and migration, intravasation, travel through lymph fluid and the bloodstream, extravasation, and reestablishment of growth at a distant site [2,9]. After the EMT of cancer cells, invasion of the basement membrane proceeds through a series of discrete steps, and various proteases predominantly control the degradation of the extracellular matrix (ECM) and the basement membrane of blood and lymph vessels [10]. Of these proteases, urokinase-type plasminogen activator (uPA), matrix metalloproteinase (MMP)-2 (gelatinase A, $72 \mathrm{kDa}$ ), and MMP-9 (gelatinase $\mathrm{B}, 92 \mathrm{kDa}$ ) are considered the most crucial enzymes for controlling the degradation of the main constituent of the ECM and are substantially involved in cancer invasion, migration, and metastasis [11,12]. Thus, suppressing uPA-, MMP-2-, or MMP-9-mediated cellular invasion and migration may generate a putative anti-metastasis effect.

Identifying molecular signaling pathways implicated in metastatic osteosarcoma contributes to the development of new therapeutic strategies available for patients who either metastasize or do not [2,3]. Several pathways, including mitogen-activated protein kinases (MAPKs), a family of serine/threonine kinases, including extracellular signal-regulated kinase (ERK) 1/2, c-Jun N-terminal kinase (JNK) 1/2 and p38, phosphoinositde 3-kinase (PI3K)/Akt, nuclear factor $\mathrm{\kappa B}(\mathrm{NF}-\mathrm{kB})$, and Janus kinase (JAK)/signal transducer and activator of transcription 3 (STAT3), are known to participate in various signaling cascades that are involved in the many cellular processes of motility, migration, invasion, and adhesion in osteosarcoma [13-16]. Therefore, activation of MAPKs, PI3K/Akt, JAK/STAT, and NF- $\mathrm{KB}$ signaling plays an important regulatory role in numerous cellular activities of osteosarcoma metastasis.

Curcumin, a phenolic compound from the natural spice turmeric (Curcuma longa) possesses pleiotropic pharmacological effects, including anti-inflammatory [17], antioxidative [18], cardiovascular protective, and anti-cancer effects [19-22]. Poor absorption, quick metabolism, and rapid systemic elimination contribute to the low plasma and tissue levels of curcumin, and therefore limit its application in anti-cancer therapy. In an effort to increase the bioavailability and pharmacokinetic profiles of curcumin, several researchers have designed and synthesized potent anti-neoplastic analogues of curcumin [23]. L48H37 [1-ethyl-3,5-bis((E)-3,4,5-trimethoxybenzylidene)piperidin-4-one], a new curcumin analogue with an unsaturated monoketone structure compared to the $\beta$-diketone structure of curcumin, was developed to increase its stability and improve its bioavailability and anti-cancer effects (Figure 1A). So far, only two studies have demonstrated the anti-cancer effects of L48H37 in lung cancer [24] and pancreatic ductal adenocarcinoma cells [25]. However, the effect of $\mathrm{L} 48 \mathrm{H} 37$ on human osteosarcoma metastasis remains to be fully delineated. We herein tested the hypothesis that $\mathrm{L} 48 \mathrm{H} 37$ affects the invasion and migration of human osteosarcoma cells and explored its underlying pathways. 
(A)<smiles>CCN1C/C(=C\c2cc(OC)c(OC)c(OC)c2)C(=O)/C(=C/c2cc(OC)c(OC)c(OC)c2)C1</smiles>

L48H37
(B)

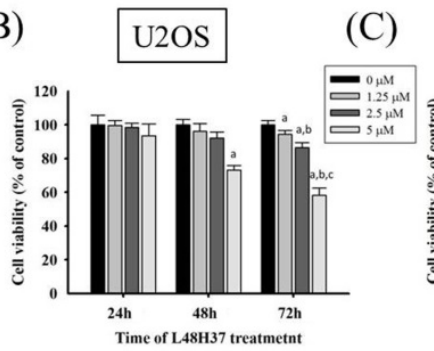

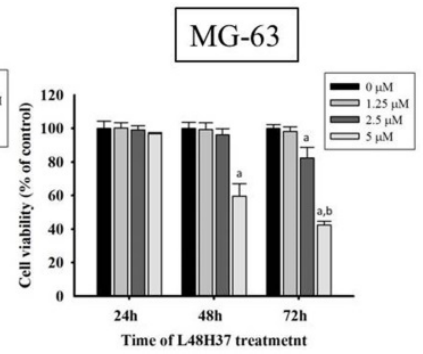

$\mathrm{U} 2 \mathrm{OS}$

(D)
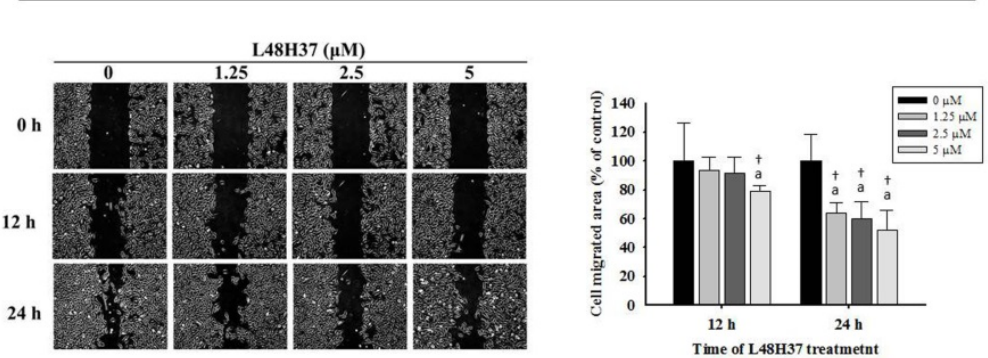

(E)
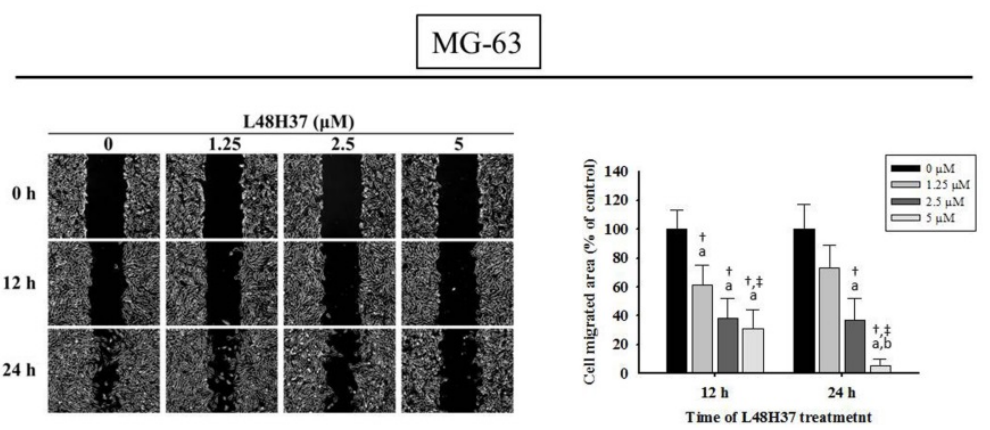

Figure 1. Effects of L48H37 on the viability of U2OS and MG-63 cells. (A) The structure of curcumin analogue L48H37. (B,C) Using an microculture tetrazolium (MTT) assay, the effects of L48H37 on the viability of U2OS and MG-63 cells treated with $\mathrm{L} 48 \mathrm{H} 37(0,1.25,2.5$, and $5 \mu \mathrm{M})$ for 24 , 48 , and $72 \mathrm{~h}$ were detected and illustrated after quantitative analysis. (D,E) The wound-healing assay after different concentrations $(0,1.25,2.5$, and $5 \mu \mathrm{M})$ of $\mathrm{L} 48 \mathrm{H} 37$ treatment for different time intervals $(0,12$, and $24 \mathrm{~h})$ in U2OS and MG-63 cells were measured, as described in the Materials and Methods section, and illustrated after quantitative analysis. $n=3$. ANOVA with Tukey's post-hoc test was used. Concentration effects: U2OS: $24 \mathrm{~h}: \mathrm{F}=7.533, p=0.010$; MG-63: $12 \mathrm{~h}: \mathrm{F}=16.333$, $p=0.001 ; 24 \mathrm{~h}: \mathrm{F}=26.228, p<0.001$. ${ }^{\text {a }}$ Significantly different, $p<0.05$, compared with the vehicle group. ${ }^{\mathrm{b}}$ Significantly different, $p<0.05$, compared with $1.25 \mu \mathrm{M}$. ${ }^{\mathrm{c}}$ Significantly different, $p<0.05$, compared with $2.5 \mu \mathrm{M}$. ${ }^{\dagger}$ Significantly different, $p<0.05$, compared with $0 \mathrm{~h}$. ‡ Significantly different, $p<0.05$, when compared with $24 \mathrm{~h}$ (U2OS) or $12 \mathrm{~h}$ (MG-63).

\section{Results}

\subsection{Cytotoxicity of L48H37 in Osteosarcoma U2OS and MG-63 Cells}

The cell viability of osteosarcoma U2OS and MG-63 cells in the presence of L48H37 with concentrations of $1.25,2.5$, and $5 \mu \mathrm{M}$ for $24 \mathrm{~h}$ was not significantly different from that of the controls $(0 \mu \mathrm{M})$ in the microculture tetrazolium (MTT) assay (U2OS: $p=0.87$; MG-63: $p=0.382$ ) (Figure 1B,C). However, after $72 \mathrm{~h}$ of treatment, the viability of U2OS and MG-63 cells in the presence of $\mathrm{L} 48 \mathrm{H} 37$ at concentrations of 2.5 and $5 \mu \mathrm{M}$ was significantly different from that of the control $(0 \mu \mathrm{M})$ (Figure $1 \mathrm{~B}, \mathrm{C})(p<0.001$ and $p<0.001)$. Thus, $24 \mathrm{~h}$ treatment with L48H37 up to $5 \mu \mathrm{M}$ had no cytotoxic effect on U2OS and MG-63 cells. We used this concentration range for $\mathrm{L} 48 \mathrm{H} 37$ in all subsequent experiments to explore its anti-metastatic properties. 


\subsection{L48H37 Represses U2OS and MG-63 Cells' Motility, Migration, and Invasion}

After treatment for $24 \mathrm{~h}$ in U2OS cells and MG-63 cells, L48H37 significantly reduced the motility of U2OS and MG-63 cells in the wound-healing assay (concentration effects: U2OS: 24 h: $p=0.010$; MG-63: 12 h: $p=0.001,24$ h: $p<0.001$ (Figure 1D,E). Moreover, the Boyden chamber assay with and without Matrigel, after treatment for $24 \mathrm{~h}$ in U2OS cells and $48 \mathrm{~h}$ in MG-63 cells, showed that L48H37 significantly and dose-dependently reduced the migratory potential and invasive activity in U2OS and MG-63 cells (migration: U2OS: $p<0.001$, MG-63: $p<0.001$; invasion: U2OS: $p<0.001$; MG-63: $p<0.001$ ) (Figure 2A-D).

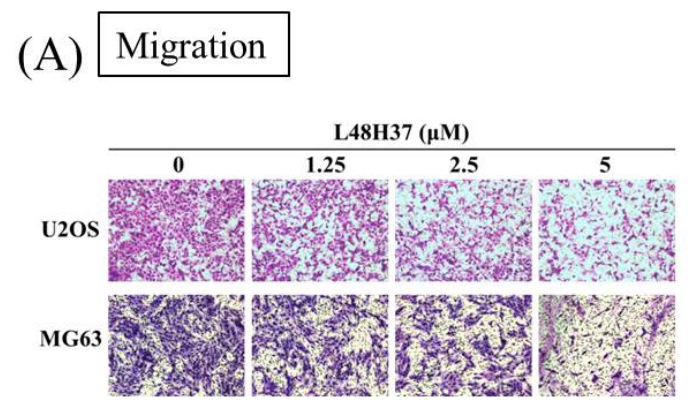

(C) Invasion

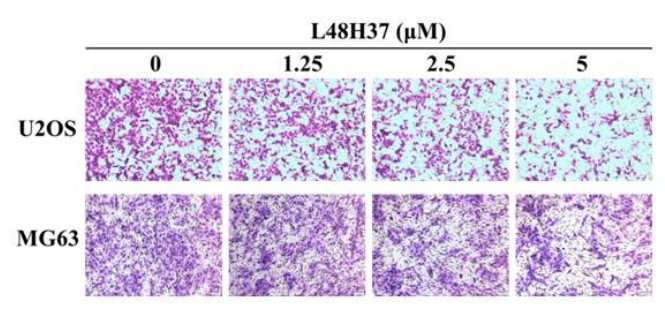

(B)

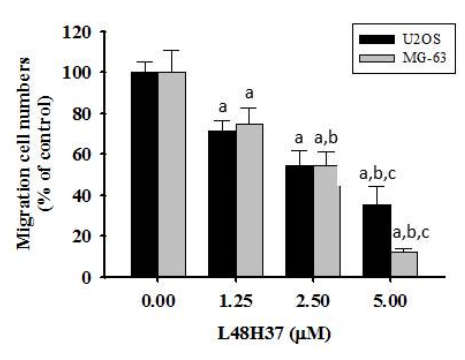

(D)

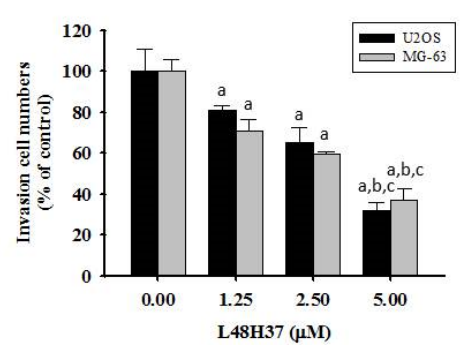

Figure 2. Effects of L48H37 on the in vitro cellular migration and invasion of U2OS and MG-63 cells. Cell migration $(\mathbf{A}, \mathbf{B})$ and invasion $(\mathbf{C}, \mathbf{D})$ assays after various concentrations $(0,1.25,2.5$, and $5 \mu \mathrm{M})$ of L48H37 treatment for $24 \mathrm{~h}$ in U2OS and $48 \mathrm{~h}$ in MG-63 cells were measured, as described in the Materials and Methods section, and illustrated after quantitative analysis. Results are shown as mean \pm SD. $N=3$. ANOVA with Tukey's post-hoc test was used. Migration: U2OS: $F=50.518$, $p<0.001$; MG-63: $\mathrm{F}=70.589, p<0.001$. Invasion: $\mathrm{U} 2 \mathrm{OS}: \mathrm{F}=51.441, p<0.001$; MG-63: $\mathrm{F}=83.112$, $p<0.001$. ${ }^{a}$ Significantly different, $p<0.05$, compared with control. ${ }^{\mathrm{b}}$ Significantly different, $p<0.05$, compared with $1.25 \mu \mathrm{M}$. ${ }^{\mathrm{c}}$ Significantly different, $p<0.05$, compared with $2.5 \mu \mathrm{M}$.

\subsection{L48H37 Reduces the Level, Protein and mRNA Expression, and Promoter Activity of uPA in U2OS Cells}

To identify the underlying mechanism of the anti-metastatic actions of L48H37 in osteosarcoma cells, we employed the protease array, which showed repression of uPA expression in U2OS cells after treatment with $5 \mu \mathrm{M}$ of L48H37 for $24 \mathrm{~h}$ (Figure 3A). We subsequently conducted casein zymography and Western blotting assay to validate the finding of the protease array and found that $\mathrm{L} 48 \mathrm{H} 37$ significantly repressed the uPA level and protein expression in the U2OS and MG-63 cells (U2OS: level: $p<0.001$; protein: $p<0.001$; MG-63: level: $p<0.001$; protein: $p<0.001$ ) (Figure 3B,C). We also conducted realtime PCR and luciferase reporter assays and found that $\mathrm{L} 48 \mathrm{H} 37$ significantly repressed the mRNA expression and promoter activity of uPA in U2OS cells (mRNA: $p<0.001$; promoter activity: $p<0.001$ ) (Figure 3D,E). We transformed cells with a small interfering RNA (siRNA)-targeting uPA expression for $24 \mathrm{~h}$ and measured the uPA protein expression in Western blotting to further confirm whether reduction in uPA interferes with the migratory 
activity of U2OS cells (Figure 3F). Subsequently, we performed Boyden chamber migration while using the siRNA of uPA for $24 \mathrm{~h}$ to compare the migratory ability and found that the knockdown of uPA significantly decreased the migratory potential of U2OS cells $(p<0.001)$ (Figure 3G).

(A)
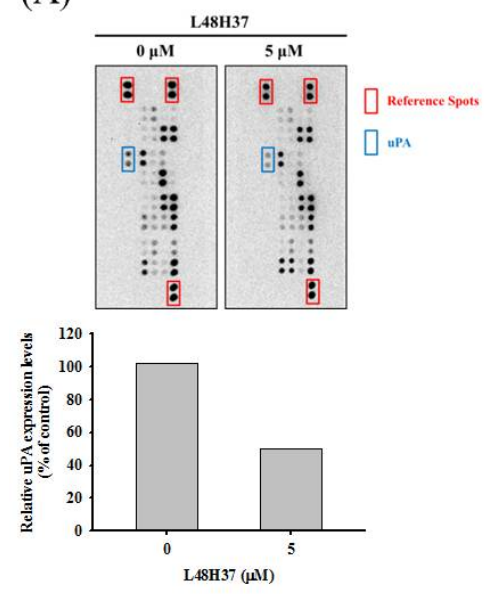

(C)
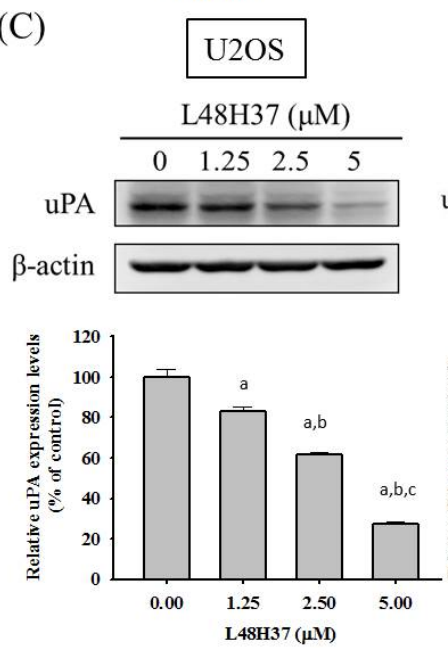

(F)

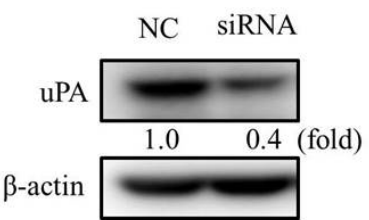

(B)
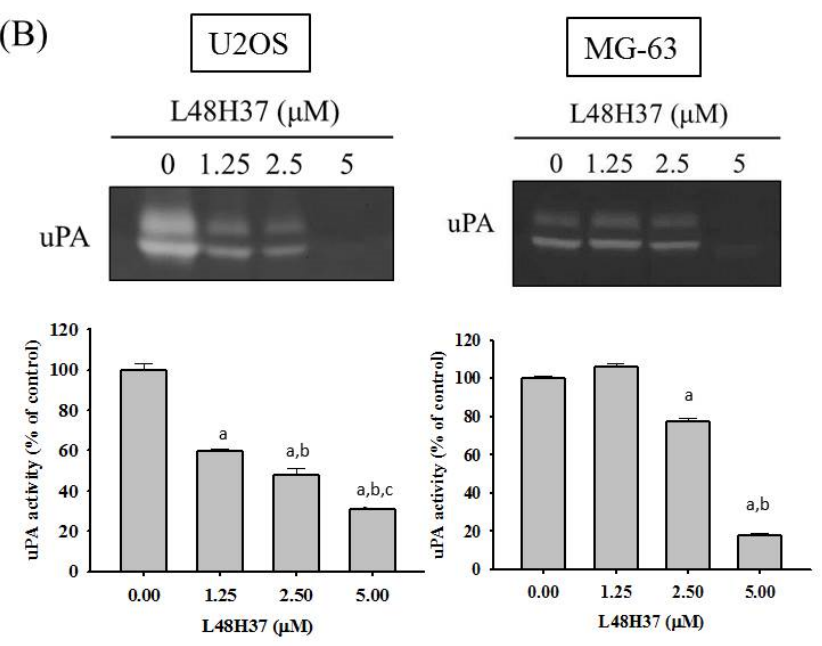

(D)

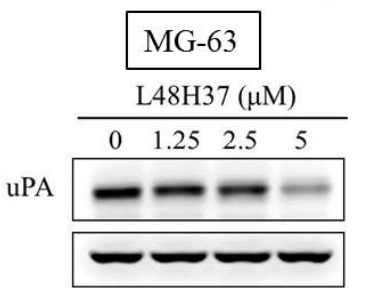

(E)
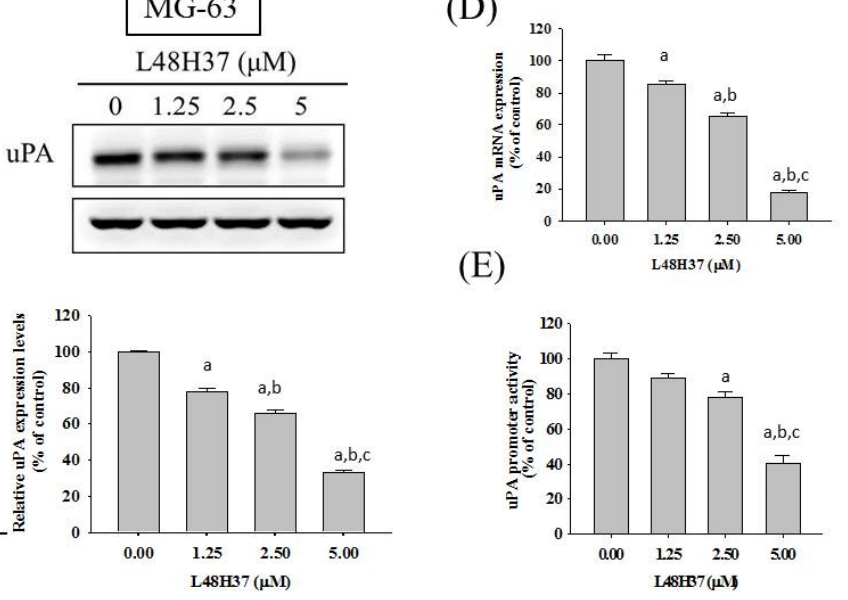

(G)

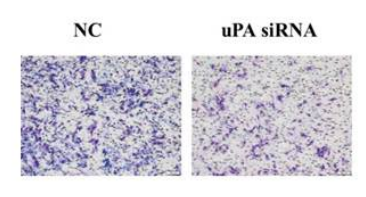

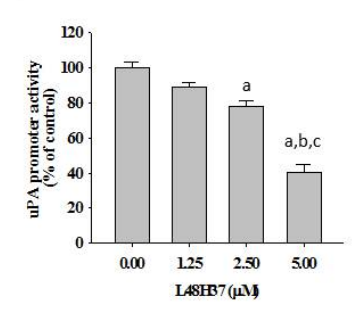

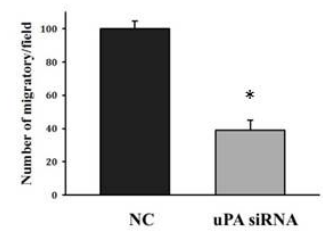

Figure 3. Expression of uPA in L48H37-treated U2OS cells. (A) The protease array, after treatment with $5 \mu \mathrm{M}$ of $\mathrm{L} 48 \mathrm{H} 37$ for $24 \mathrm{~h}$ in U2OS cells, was employed, as described in the Materials and Methods section, and illustrated after quantitative analysis. (B) Casein zymography, (C) Western blotting analysis, (D) real-time PCR, and (E) luciferase reporter assay, after treatment with $\mathrm{L} 48 \mathrm{H} 37$ at various concentrations $(0,1.25,2.5$, and $5 \mu \mathrm{M})$ for $24 \mathrm{~h}$ in U2OS cells were conducted as described in the Materials and Methods section. Results are shown as mean \pm SD. $n=3$. ANOVA with Tukey's post-hoc test was used. ${ }^{a}$ Significantly different, $p<0.05$, compared with control. ${ }^{\mathrm{b}}$ Significantly different, $p<0.05$, compared with $1.25 \mu \mathrm{M}$. ${ }^{c}$ Significantly different, $p<0.05$, compared with $2.5 \mu \mathrm{M}$. (F) Western blotting assay to confirm siRNA directly against uPA expression and (G) Boyden chamber assay after treatment of uPA siRNA for $24 \mathrm{~h}$ in U2OS cells were conducted, and the effects were illustrated after quantitative analysis. Student's $t$-test was used. ${ }^{*}$ Significantly different, $p<0.05$ compared with the negative control (NC) group. 


\subsection{L48H37 Suppresses the JAK/STAT Pathway in U2OS Cells}

Since MAPK and PI3K pathways may be upstream signaling for uPA, Western blotting was employed to further investigate the molecular mechanisms. In the analysis, MAPK and PI3K/Akt pathways were detected in U2OS cells. As a result, however, $\mathrm{L} 48 \mathrm{H} 37$ had no obvious influence on ERK 1/2, JNK 1/2, p38, or Akt, including their phosphorylation (ERK: $p=0.518$, JNK: $p=0.096$, p38: $p=0.518$, Akt: $p=0.355$ ) (Figure 4A-D). Furthermore, we explored the JAK/STAT pathway and intriguingly found that $\mathrm{L} 48 \mathrm{H} 37$ decreased the phosphorylation of STAT3 and JAK 1/2/3 in U2OS cells (STAT3: $p<0.001$, JAK1: $p<0.001$, JNK2: $p<0.001$, JNK3: $p<0.001$ ) (Figure 4E-H).

(A)
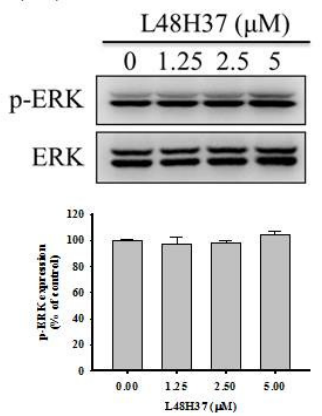

(E)

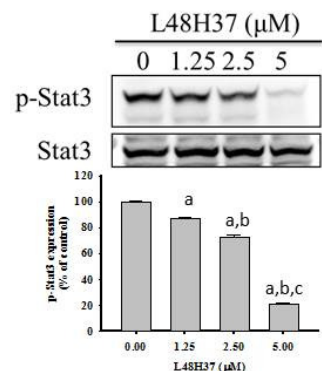

(B)
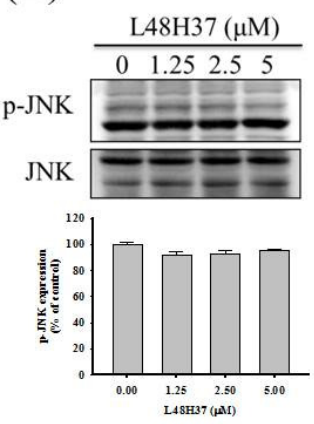

(F)

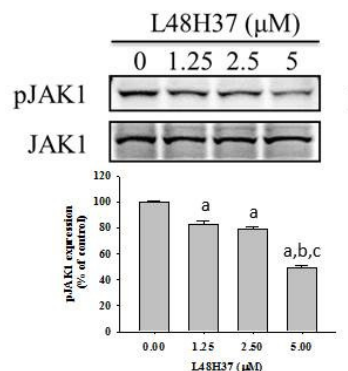

(C)
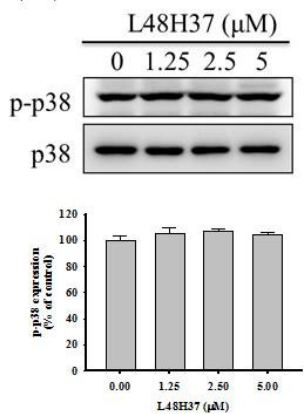

(G)

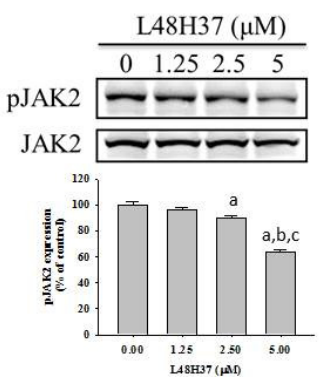

(D)
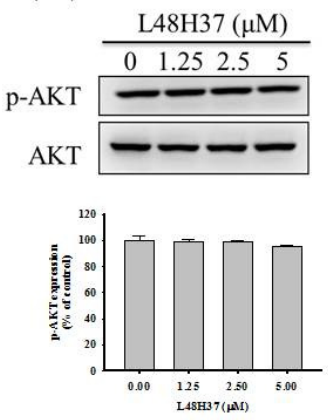

(H)

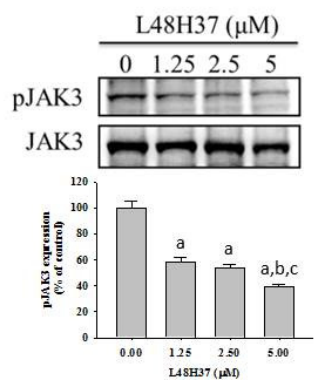

Figure 4. Effects of L48H37 on MAPKs, PI3K-Akt, STAT3, and JAK1/2/3 in U2OS cells. Western blotting analyses for the total or phosphorylated forms of (A) ERK, (B) JNK, (C) p38, (D) Akt, (E) STAT3, (F) JAK1, (G) JAK2, and (H) JAK3 after treatment with L48H37 at various concentrations (0, $1.25,2.5$, and $5 \mu \mathrm{M}$ ) for $24 \mathrm{~h}$ in U2OS cells were conducted as described in the Materials and Methods section. The effects were illustrated after quantitative analysis. Results are shown as mean \pm SD. $n=3$. ANOVA with Tukey's post-hoc test was used. ERK: $\mathrm{F}=0.820, p=0.518$; JNK: $\mathrm{F}=2.986, p=0.096$; p38: $\mathrm{F}=0.821, p=0.518$; Akt: $\mathrm{F}=1.247, p=0.355$; STAT3: $\mathrm{F}=1074.631, p<0.001 ; \mathrm{JAK} 1: \mathrm{F}=140.865$, $p<0.001$; JNK2: $\mathrm{F}=68.922, p<0.001$; JNK3: $\mathrm{F}=67.086, p<0.001$. ${ }^{a}$ Significantly different, $p<0.05$, compared with control. ${ }^{\mathrm{b}}$ Significantly different, $p<0.05$, compared with $1.25 \mu \mathrm{M}$. ${ }^{\mathrm{c}}$ Significantly different, $p<0.05$, compared with $2.5 \mu \mathrm{M}$.

\subsection{L48H37 Inhibits Cellular Migration and uPA Expression via the JAK/STAT Pathway in U2OS Cells}

To recognize whether the suppression of STAT3 and JAK $1 / 2 / 3$ phosphorylation by L48H37 interferes with the actions of uPA secretion and migration potential by L48H37 in U2OS cells, an inhibitor of STAT3 (C188-9) was used. As shown in Figure 5A,B, cell migration potential and uPA expression in the U2OS cells were repressed by C188-9. We also used an activator of STAT3 $(2 \mu \mathrm{M}$ of colivelin) with or without treatment with 2.5 $\mu \mathrm{M}$ of $\mathrm{L} 48 \mathrm{H} 37$ in U2OS cells. Migration potential and uPA expression were repressed by L48H37 (migration: $p=0.013$ ) and activated by colivelin (migration: $p<0.001$ ), as expected (Figure 5C,D). Intriguingly, colivelin significantly countered the decrease in migration potential and uPA expression in U2OS cells caused by L48H37 (migration: $p<0.001$ ). 
Overall, these findings indicated that the JAK/STAT pathway plays a critical upstream role in L48H37-inhibited migration potential and uPA expression in U2OS cells.

(A)

(C)
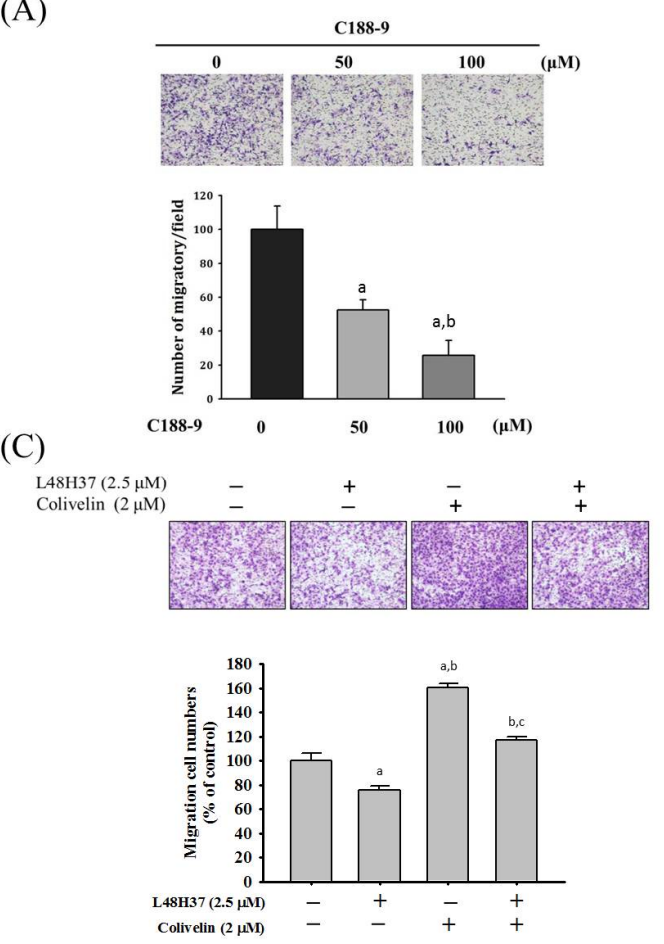

(B)

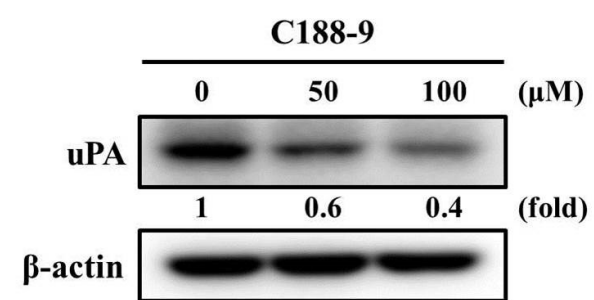

(D)

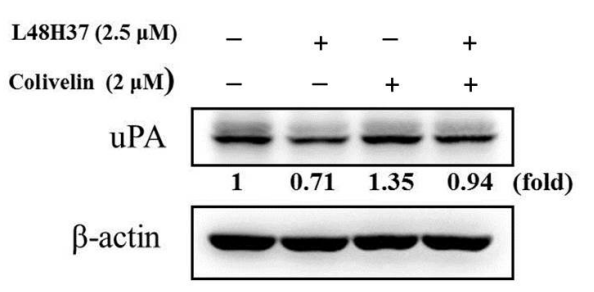

Figure 5. Effects of STAT3 inhibitor (C188-9) and activator (colivelin) on cell migration and uPA expression in L48H37-treated U2OS cells. (A) Migratory potential and (B) uPA expression after treatment of 50 and $100 \mu \mathrm{M}$ of $\mathrm{C} 188-9$ for $24 \mathrm{~h}$ in U2OS cells were measured through Boyden chamber assays and Western blotting analysis. ${ }^{a}$ Significantly different, $p<0.05$, compared with control. ${ }^{\mathrm{b}}$ Significantly different, $p<0.05$, compared with $50 \mu \mathrm{M}$ of C188-9. (C) Migratory potential and (D) uPA expression after pretreatment with or without $2 \mu \mathrm{M}$ of colivelin for $1 \mathrm{~h}$, followed by treatment with or without $2.5 \mu \mathrm{M}$ of $\mathrm{L} 48 \mathrm{H} 37$ for an additional $24 \mathrm{~h}$ in U2OS cells, were measured through Boyden chamber assays and Western blotting analysis. The effects were illustrated after quantitative analysis. Results are shown as mean \pm SD. $n=3$. ANOVA with Tukey's post-hoc test was used. Migration: $\mathrm{F}=76.962, p<0.001 ; \mathrm{uPA}: \mathrm{F}=220.752, p<0.001$. ${ }^{a}$ Significantly different, $p<0.05$, compared with control. ${ }^{\mathrm{b}}$ Significantly different, $p<0.05$, compared with $2.5 \mu \mathrm{M}$ of L48H37. ${ }^{c}$ Significantly different, $p<0.05$, compared with $2 \mu \mathrm{M}$ of colivelin.

\section{Discussion}

Although curcumin is a promising molecule to suppress the various metastatic properties of osteosarcoma cells $[16,26]$, its low solubility in water and instability due to its chemical structure change result in poor bioavailability, about $75 \%$ of oral intake is excreted through the feces [27]. To effectively harness the anti-metastatic activity of curcumin, improve its pharmacokinetic properties and stability, enhance its ability for intravenous administration, and achieve prolonged half-lives, several curcumin analogues have been engineered [27]. The promising curcumin analogue L48H37 not only induces apoptosis through ROS-mediated endoplasmic reticulum stress and STAT3 pathways in human lung cancer cells [24] but also exerts a potent anti-cancer effect in human pancreatic ductal adenocarcinoma cells, which is augmented by histonelysine $N$-methyltransferase 2D [25].

In the present study, we investigated the anti-metastatic effects of $\mathrm{L} 48 \mathrm{H} 37$ that can attenuate the cellular motility, migratory potential, and invasive ability of U2OS and MG-63 cells under a non-cytotoxic concentration range. Although MMP-2 and MMP-9 are well known to be key enzymes and contributed to the process of osteosarcoma cell metastases in our previous research [13,28-30], no effects of L48H37 on MMP-2 and MMP-9 
secretion in U2OS cells were observed. Interestingly, repression of uPA protein expression in U2OS cells was detected after treatment with $5 \mu \mathrm{M}$ of L48H37 in the protease array, and the L48H37-induced repression of UPA was verified using casein zymography, Western blotting, real-time PCR, and luciferase reporter assay. Through further analysis of upstream signaling, L48H37 decreased the phosphorylation of STAT3 and JAK 1/2/3 in U2OS cells, whereas there was no evident influence on ERK 1/2, JNK 1/2, p38, and Akt, or on their phosphorylation. The decrease in migratory potential and uPA expression in U2OS cells, caused by L48H37, was countered by activation of STAT3 colivelin. These results implied that $\mathrm{L} 48 \mathrm{H} 37$ 's inhibition of migration in human osteosarcoma U2OS cells results from the attenuation of uPA, not MMP-2 or MMP-9, through the JAK/STAT pathway rather than MAPK and PI3K/Akt signaling. However, in Figure 5C,D, a very marginal increase in uPA expression correlates with a much more striking increase in migratory potential after treatment with colivelin. These are indications that STAT activation likely activates other downstream effectors in addition to uPA and may warrant further studies.

The diverse MAPK members PI3K/Akt and STAT3 are activated in response to various extracellular stimuli and have distinct downstream targets, including cell motility, migration, invasion, proteinase induction, and angiogenesis, which all contribute to metastasis [31-35], so they have been implicated as oncogenes and therapeutic targets in a variety of neoplastic diseases. In human osteosarcoma SJSA and U2OS cell lines, a structure-based curcumin analogue, FLLL32, simultaneously decreases STAT3 DNA-binding activity, and expression of survivin, VEGF, and MMP-2 at both mRNA and protein levels, with concurrent decreases in phosphorylated and total STAT3, to promote loss of cell proliferation, leading to caspase-3-dependent apoptosis [36]. In MG-63 cells, curcumin dose-dependently decreases pJAK-2 and pSTAT-3 expression not only to induce cell cycle arrest and apoptosis but also to inhibit cellular migration and invasion [16]. As mentioned earlier, through ROS-mediated endoplasmic reticulum stress and STAT3 pathways to induce apoptosis in human lung cancer cells [24], L48H37 also repressed uPA via the JAK/STAT signaling to suppress the migration of human osteosarcoma U2OS cells in the present study.

\section{Materials and Methods}

\subsection{Materials}

Cell culture materials, including Dulbecco's modified Eagle medium (DMEM) and fetal bovine serum (FBS), were obtained from Gibco Life Technologies (Gaithersburg, MD, USA) and Hyclone Laboratories, Inc. (Logan, UT, USA), respectively. Antibodies specifically for $\beta$-actin, Akt, and p38 were obtained from BD Biosciences (San Jose, CA, USA). Antibodies specific for phosphorylated ERK 1/2, JNK 1/2, Akt, STAT3, and JAK 1/2/3, as well as ERK 1/2, JNK 1/2, STAT3, and JAK 1/2/3, were purchased from Cell Signaling Technology (Danvers, MA, USA). Human uPA siRNA (s10610) and negativecontrol siRNA (4390844) were purchased from Applied Biosystems Instruments (Foster City, CA, USA). The Human Protease Assay Kit was acquired from R\&D Systems (Minneapolis, MN, USA). L48H37 and the inhibitor of STAT3 (C188-9) were bought from Sigma-Aldrich (St. Louis, MO, USA). The activator of STAT3 (colivelin) was bought from Santa Cruz Biotechnology, Inc. (Dallas, TX, USA).

\subsection{Cell Culture and L48H37 Treatment}

Human osteosarcoma U2OS (15-year-old female) and MG-63 (14-year-old male) cells, obtained from the Food Industry Research and Development Institute (Hsinchu, Taiwan), were supplemented with 10\% FBS, 1\% penicillin/streptomycin, and $5 \mathrm{~mL}$ of glutamine, cultured in DMEM, and maintained at $37{ }^{\circ} \mathrm{C}$ in the humidified atmosphere of a $5 \% \mathrm{CO}_{2}$ incubator, as described previously [14].

\subsection{MTT Assay}

To investigate the cytotoxicity of L48H37, the MTT colorimetric assay was conducted. We plated $8 \times 10^{4}$ / well U2OS and MG-63 cells in 24-well plates for $16 \mathrm{~h}$ and tested different 
concentrations $(0,1.25,2.5$, and $5 \mu \mathrm{M})$ of $\mathrm{L} 48 \mathrm{H} 37$ at $37^{\circ} \mathrm{C}$ for $24 \mathrm{~h}$. After the exposure period, an MTT assay was carried out, as reported previously [32,37].

\subsection{Wound-Healing Assay}

For cellular motility, a total of $2.4 \times 10^{6} \mathrm{U} 2 \mathrm{OS}$ cells and $1.5 \times 10^{6} \mathrm{MG}-63$ cells in $6 \mathrm{~cm}$ dishes were plated for $16 \mathrm{~h}$, wounded by scratching with a pipette tip, and then incubated with DMEM containing $0.5 \%$ FBS. We tested the indicated concentrations of L48H37 (0, $1.25,2.5$, and $5 \mu \mathrm{M}$ ) in U2OS cells for 0,12 , and $24 \mathrm{~h}$, and MG-63 cells for 0,12 , and $24 \mathrm{~h}$, respectively. The cells were photographed using a phase-contrast microscope $(100 \times)$ to determine the width of the remaining wound area relative to the initial wound width, as depicted previously [30,37].

\subsection{Cell Migration and Invasion Assays}

To test the effect of L48H37 on the migratory potential and invasive ability of U2OS and MG-63 cells in vitro, we employed a modified Boyden chamber migration assay with and without Matrigel coating, respectively. After treatment with L48H37 with concentrations of $0,1.25,2.5$, and $5 \mu \mathrm{M}$, the cells were seeded into the upper section of the Boyden chamber (Neuro Probe, Cabin John, MD, USA) at a density of $2 \times 10^{5} / \mathrm{mL}$ for U2OS cells and $4 \times 10^{5} / \mathrm{mL}$ for MG-63 cells, and then the U2OS cells and MG-63 cells were incubated in the modified Boyden chamber migration assay and invasion assay at $37{ }^{\circ} \mathrm{C}$ for $24 \mathrm{~h}$ and $48 \mathrm{~h}$, respectively. Under a light microscope, the migratory and invasive cells were finally counted, as stated previously [32,37-39].

\subsection{Protease Array Analysis}

To determine metastasis-related proteins induced by $\mathrm{L} 48 \mathrm{H} 37$, a protease (35 proteases) array analysis was employed to evaluate the protein lysates of $2 \times 10^{6}$ U2OS cells from vehicle- or $5 \mu \mathrm{M}$ L48H37-treated cells, according to the manufacturer's protocols (R\&D Systems, Minneapolis, MN, USA).

\subsection{Preparation of Cell Lysates and Western Blotting Analysis}

To validate the protease array findings and to further explore the molecular mechanism and signaling pathways, Western blotting analysis was conducted. We plated $8 \times 10^{5}$ U2OS and MG-63 cells in $6 \mathrm{~cm}$ dishes for $16 \mathrm{~h}$ and tested them with different concentrations $(0,1.25,2.5$, and $5 \mu \mathrm{M})$ of L48H37 for $24 \mathrm{~h}$. The total cell lysates of U2OS and MG-63 cells were prepared, as described previously [29,32,37]. Western blotting analysis was performed using either specific primary antibodies against three MAPKs (ERK 1/2, JNK 1/2, and p38), Akt, STAT3, and JAK 1/2/3 or with the specific antibodies for unphosphorylated or phosphorylated forms of the corresponding ERK 1/2, JNK 1/2, p38, Akt, STAT3, and JAK $1 / 2 / 3$. As described previously, the blots were then incubated with a horseradish peroxidase goat anti-rabbit or anti-mouse IgG for $1 \mathrm{~h}$, and the intensity of each band was measured by densitometry $[29,32,37]$.

\subsection{Real-Time Polymerase Chain Reaction (PCR)}

With the following modification, a real-time PCR assay was performed, as described previously [32]. Specific primers and fluorogenic probes were used for the uPA gene.

\section{9. uPA Promoter-Driven Luciferase Reporter Assay}

We plated $8 \times 10^{4} /$ well U2OS cells in 6-well plates with treatments of $0,1.25,2.5$, and $5 \mu \mathrm{M}$ L48H37 for $24 \mathrm{~h}$. As stated previously, the pGL3-basic vector (pGL3-control vector) and pGL3-uPA promoter were co-transfected with a $\beta$-galactosidase expression vector. After $24 \mathrm{~h}$ of transfection, the cell lysates were harvested and luciferase activity was determined using a luciferase assay kit. The value of the luciferase activity was normalized to transfection efficiency and monitored by $\beta$-galactosidase expression [37]. 


\subsection{Statistical Analysis}

For all of the measurements, analysis of variance was followed by one-way analysis of variance with Scheffe's and Tukey's post-hoc test for more than two groups with unequal and equal sample sizes per group, respectively. When two groups were compared, the data were analyzed while using Student's t-test. Each experiment was repeated independently at least three times $(n \geq 3)$. $p$ values $<0.05$ were considered statistically significant.

\section{Conclusions}

In conclusion, the new curcumin analogue L48H37 contributes to the suppression of cellular invasion and migration by inhibition of UPA and the JAK/STAT pathway, not via ERK, JNK, p38, and PI3K/Akt signaling. This phenomenon of uPA repression of invasion and migration in U2OS and MG-63 cells could be activated by colivelin, an activator of STAT3. Our results reinforce the hypothesis that $\mathrm{L} 48 \mathrm{H} 37$ possesses the ability to inhibit invasion and migration on human osteosarcoma cells, which provides evidence of being a potential candidate for anti-metastasis of human osteosarcoma, as well as a better understanding of the mechanisms responsible for these effects. In the future, the determination of the therapeutic efficacy and pharmacodynamics properties of $\mathrm{L} 48 \mathrm{H} 37$ on osteosarcoma metastasis in vivo is imperative.

Author Contributions: Conceptualization, K.-H.L., H.-H.W., S.-F.Y., and J.-S.Y.; methodology, R.-C.L., Y.-C.L., P.W.-A.L., and J.-S.Y.; validation, K.-H.L., S.-F.Y., and J.-S.Y.; writing-original draft preparation, K.-H.L., H.-H.W., S.-F.Y., and J.-S.Y.; writing - review and editing, K.-H.L., S.-F.Y., and J.-S.Y. All authors have read and agreed to the published version of the manuscript.

Funding: This research was funded by Chung Shan Medical University Hospital, Taiwan, grant number CSH-2020-D-001.

Data Availability Statement: The data presented in this study are available in this article.

Conflicts of Interest: The authors declare no conflict of interest.

Sample Availability: Not available.

\section{References}

1. Arndt, C.A.; Rose, P.S.; Folpe, A.L.; Laack, N.N. Common musculoskeletal tumors of childhood and adolescence. Mayo Clin. Proc. 2012, 87, 475-487. [CrossRef]

2. Lu, K.H.; Lin, C.W.; Hsieh, Y.H.; Su, S.C.; Reiter, R.J.; Yang, S.F. New insights into antimetastatic signaling pathways of melatonin in skeletomuscular sarcoma of childhood and adolescence. Cancer Metastasis Rev. 2020, 39, 303-320. [CrossRef]

3. Lu, K.H.; Lu, E.W.; Lin, C.W.; Yang, J.S.; Yang, S.F. New insights into molecular and cellular mechanisms of zoledronate in human osteosarcoma. Pharmacol. Ther. 2020, 107611. [CrossRef]

4. Arndt, C.A.; Crist, W.M. Common musculoskeletal tumors of childhood and adolescence. N. Engl. J. Med. 1999, $341,342-352$. [CrossRef]

5. Ottaviani, G.; Jaffe, N. The epidemiology of osteosarcoma. Cancer Treat. Res. 2009, 152, 3-13.

6. $\quad$ Oertel, S.; Blattmann, C.; Rieken, S.; Jensen, A.; Combs, S.E.; Huber, P.E.; Bischof, M.; Kulozik, A.; Debus, J.; Schulz-Ertner, D. Radiotherapy in the treatment of primary osteosarcoma-a single center experience. Tumori 2010, 96, 582-588. [CrossRef]

7. Lu, K.H.; Lin, R.C.; Yang, J.S.; Yang, W.E.; Reiter, R.J.; Yang, S.F. Molecular and cellular mechanisms of melatonin in osteosarcoma. Cells 2019, 8, 1618. [CrossRef]

8. Su, S.C.; Hsieh, M.J.; Yang, W.E.; Chung, W.H.; Reiter, R.J.; Yang, S.F. Cancer metastasis: Mechanisms of inhibition by melatonin. J. Pineal Res. 2017, 62, e12370. [CrossRef]

9. Gupta, G.P.; Massague, J. Cancer metastasis: Building a framework. Cell 2006, 127, 679-695. [CrossRef]

10. Yoon, S.O.; Park, S.J.; Yun, C.H.; Chung, A.S. Roles of matrix metalloproteinases in tumor metastasis and angiogenesis. J. Biochem. Mol. Biol. 2003, 36, 128-137. [CrossRef]

11. Mackay, A.R.; Corbitt, R.H.; Hartzler, J.L.; Thorgeirsson, U.P. Basement membrane type iv collagen degradation: Evidence for the involvement of a proteolytic cascade independent of metalloproteinases. Cancer Res. 1990, 50, 5997-6001.

12. Nelson, A.R.; Fingleton, B.; Rothenberg, M.L.; Matrisian, L.M. Matrix metalloproteinases: Biologic activity and clinical implications. J. Clin. Oncol. 2000, 18, 1135-1149. [CrossRef]

13. Cheng, H.L.; Hsieh, M.J.; Yang, J.S.; Lin, C.W.; Lue, K.H.; Lu, K.H.; Yang, S.F. Nobiletin inhibits human osteosarcoma cells metastasis by blocking erk and jnk-mediated mmps expression. Oncotarget 2016, 7, 35208-35223. [CrossRef] 
14. Cheng, H.L.; Lin, C.W.; Yang, J.S.; Hsieh, M.J.; Yang, S.F.; Lu, K.H. Zoledronate blocks geranylgeranylation not farnesylation to suppress human osteosarcoma u2os cells metastasis by emt via rho a activation and fak-inhibited jnk and p38 pathways. Oncotarget 2016, 7, 9742-9758. [CrossRef]

15. Lu, J.; Song, G.; Tang, Q.; Zou, C.; Han, F.; Zhao, Z.; Yong, B.; Yin, J.; Xu, H.; Xie, X.; et al. Irx1 hypomethylation promotes osteosarcoma metastasis via induction of cxcl14/nf-kappab signaling. J. Clin. Investig. 2015, 125, 1839-1856. [CrossRef]

16. Sun, Y.; Liu, L.; Wang, Y.; He, A.; Hu, H.; Zhang, J.; Han, M.; Huang, Y. Curcumin inhibits the proliferation and invasion of mg-63 cells through inactivation of the p-jak2/p-stat3 pathway. Onco. Targets 2019, 12, 2011-2021. [CrossRef]

17. Lestari, M.L.; Indrayanto, G. Curcumin. Profiles Drug Subst Excip Relat Methodol 2014, 39, 113-204.

18. Menon, V.P.; Sudheer, A.R. Antioxidant and anti-inflammatory properties of curcumin. Adv. Exp. Med. Biol. 2007, 595, 105-125.

19. Prasad, S.; Gupta, S.C.; Tyagi, A.K.; Aggarwal, B.B. Curcumin, a component of golden spice: From bedside to bench and back. Biotechnol Adv. 2014, 32, 1053-1064. [CrossRef]

20. Seo, J.A.; Kim, B.; Dhanasekaran, D.N.; Tsang, B.K.; Song, Y.S. Curcumin induces apoptosis by inhibiting sarco/endoplasmic reticulum ca2+ atpase activity in ovarian cancer cells. Cancer Lett. 2016, 371, 30-37. [CrossRef]

21. James, M.I.; Iwuji, C.; Irving, G.; Karmokar, A.; Higgins, J.A.; Griffin-Teal, N.; Thomas, A.; Greaves, P.; Cai, H.; Patel, S.R.; et al. Curcumin inhibits cancer stem cell phenotypes in ex vivo models of colorectal liver metastases, and is clinically safe and tolerable in combination with folfox chemotherapy. Cancer Lett. 2015, 364, 135-141. [CrossRef]

22. Vallianou, N.G.; Evangelopoulos, A.; Schizas, N.; Kazazis, C. Potential anticancer properties and mechanisms of action of curcumin. Anticancer Res. 2015, 35, 645-651. [PubMed]

23. Wu, J.; Zhang, Y.; Cai, Y.; Wang, J.; Weng, B.; Tang, Q.; Chen, X.; Pan, Z.; Liang, G.; Yang, S. Discovery and evaluation of piperid-4-one-containing mono-carbonyl analogues of curcumin as anti-inflammatory agents. Bioorg. Med. Chem. 2013, 21, 3058-3065. [CrossRef]

24. Feng, C.; Xia, Y.; Zou, P.; Shen, M.; Hu, J.; Ying, S.; Pan, J.; Liu, Z.; Dai, X.; Zhuge, W.; et al. Curcumin analogue 148 h37 induces apoptosis through ros-mediated endoplasmic reticulum stress and stat 3 pathways in human lung cancer cells. Mol. Carcinogenes 2017, 56, 1765-1777. [CrossRef]

25. Li, S.S.; Jiang, W.L.; Xiao, W.Q.; Li, K.; Zhang, Y.F.; Guo, X.Y.; Dai, Y.Q.; Zhao, Q.Y.; Jiang, M.J.; Lu, Z.J.; et al. Kmt2d deficiency enhances the anti-cancer activity of $148 \mathrm{~h} 37$ in pancreatic ductal adenocarcinoma. World J. Gastrointest Oncol. 2019, 11, 599-621. [CrossRef]

26. Angulo, P.; Kaushik, G.; Subramaniam, D.; Dandawate, P.; Neville, K.; Chastain, K.; Anant, S. Natural compounds targeting major cell signaling pathways: A novel paradigm for osteosarcoma therapy. J. Hematol Oncol. 2017, 10, 10. [CrossRef]

27. Anand, P.; Kunnumakkara, A.B.; Newman, R.A.; Aggarwal, B.B. Bioavailability of curcumin: Problems and promises. Mol. Pharm. 2007, 4, 807-818. [CrossRef]

28. Chang, P.Y.; Hsieh, M.J.; Hsieh, Y.S.; Chen, P.N.; Yang, J.S.; Lo, F.C.; Yang, S.F.; Lu, K.H. Tricetin inhibits human osteosarcoma cells metastasis by transcriptionally repressing mmp-9 via p38 and akt pathways. Environ. Toxicol. 2017, 32, 2032-2040. [CrossRef]

29. Lu, K.H.; Chen, P.N.; Hsieh, Y.H.; Lin, C.Y.; Cheng, F.Y.; Chiu, P.C.; Chu, S.C.; Hsieh, Y.S. 3-hydroxyflavone inhibits human osteosarcoma u2os and 143b cells metastasis by affecting emt and repressing u-pa/mmp-2 via fak-src to mek/erk and rhoa/mlc2 pathways and reduces 143b tumor growth in vivo. Food Chem. Toxicol. 2016, 97, 177-186. [CrossRef]

30. Yang, J.S.; Lin, C.W.; Hsieh, Y.S.; Cheng, H.L.; Lue, K.H.; Yang, S.F.; Lu, K.H. Selaginella tamariscina (beauv.) possesses antimetastatic effects on human osteosarcoma cells by decreasing mmp-2 and mmp-9 secretions via p38 and akt signaling pathways. Food Chem. Toxicol. 2013, 59, 801-807. [CrossRef]

31. Reddy, K.B.; Nabha, S.M.; Atanaskova, N. Role of map kinase in tumor progression and invasion. Cancer Metastasis Rev. 2003, 22, 395-403. [CrossRef] [PubMed]

32. Hsieh, Y.S.; Chu, S.C.; Yang, S.F.; Chen, P.N.; Liu, Y.C.; Lu, K.H. Silibinin suppresses human osteosarcoma mg-63 cell invasion by inhibiting the erk-dependent c-jun/ap-1 induction of mmp-2. Carcinogenesis 2007, 28, 977-987. [CrossRef]

33. Lu, K.H.; Su, S.C.; Lin, C.W.; Hsieh, Y.H.; Lin, Y.C.; Chien, M.H.; Reiter, R.J.; Yang, S.F. Melatonin attenuates osteosarcoma cell invasion by suppression of c-c motif chemokine ligand 24 through inhibition of the c-jun n-terminal kinase pathway. J. Pineal. Res. 2018, 65, e12507. [CrossRef]

34. Zhang, T.; Li, J.; Yin, F.; Lin, B.; Wang, Z.; Xu, J.; Wang, H.; Zuo, D.; Wang, G.; Hua, Y. , et al. Toosendanin demonstrates promising antitumor efficacy in osteosarcoma by targeting stat3. Oncogene 2017, 36, 6627-6639. [CrossRef]

35. Hsieh, M.H.; Yang, J.S.; Lin, R.C.; Hsieh, Y.H.; Yang, S.F.; Chang, H.R.; Lu, K.H. Tomatidine represses invasion and migration of human osteosarcoma u2os and hos cells by suppression of presenilin 1 and c-raf-mek-erk pathway. Molecules 2020, 25, 326. [CrossRef]

36. Fossey, S.L.; Bear, M.D.; Lin, J.; Li, C.; Schwartz, E.B.; Li, P.K.; Fuchs, J.R.; Fenger, J.; Kisseberth, W.C.; London, C.A. The novel curcumin analogue flll32 decreases stat3 DNA binding activity and expression, and induces apoptosis in osteosarcoma cell lines. BMC Cancer 2011, 11, 112. [CrossRef]

37. Lu, K.H.; Yang, H.W.; Su, C.W.; Lue, K.H.; Yang, S.F.; Hsieh, Y.S. Phyllanthus urinaria suppresses human osteosarcoma cell invasion and migration by transcriptionally inhibiting u-pa via erk and akt signaling pathways. Food Chem. Toxicol. 2013, 52, 193-199. [CrossRef] 
38. Chu, S.C.; Yang, S.F.; Liu, S.J.; Kuo, W.H.; Chang, Y.Z.; Hsieh, Y.S. In vitro and in vivo antimetastatic effects of terminalia catappa 1. Leaves on lung cancer cells. Food Chem. Toxicol. 2007, 45, 1194-1201. [CrossRef] [PubMed]

39. Hsieh, M.J.; Lin, C.W.; Yang, S.F.; Chen, M.K.; Chiou, H.L. Glabridin inhibits migration and invasion by transcriptional inhibition of matrix metalloproteinase 9 through modulation of $\mathrm{nf}-\mathrm{kb}$ and ap-1 activity in human liver cancer cells. Br. J. Pharm. 2014, 171, 3037-3050. [CrossRef] [PubMed] 